\title{
Anthony S. Rausch: Cultural commodities in Japanese rural revitalization; Tsugaru Nuri Lacquerware and Tsugaru Shamisen
}

\author{
Brill, 2010, ISBN: 9789004179967
}

\author{
Robert C. Kloosterman
}

Published online: 21 November 2010

(C) The Author(s) 2010. This article is published with open access at Springerlink.com

This book tells the story of two rather particular cultural industries located in a poor, peripheral backwater in Japan. Both of them stem from a long-standing local tradition, and while one is rather successful-the Tsugaru Shamisen music performance tradition-the other one-the Tsugaru Nuri lacquerware-seems to be struggling. Given the relative marginality of even the more successful case of Tsugaru Shamisen music compared to let's say world-famous Japanese architectural design, one could question the broader relevance of this book. What contributions does this study make to wider social science debates transcending these two rather specific cultural industries? Before getting into more detail, there is indeed plenty that should appeal to readers who are interested in more general issues concerning the (potential) role of local cultural industries in revitalizing rural regions. Notably, the analysis of the long-term dynamics of cultural industries which encompasses both the production and the consumption side, and the dissection of the impact of active government intervention deserves a much wider audience than just those who are interested in either Japanese lacquerware or music. Moreover, the strategic importance of this study lies in the fact that it addresses the pressing question of how poor, peripheral rural areas may benefit from the presence of local cultural industries to boost their local economy. From this perspective, the Tsugara District is well chosen indeed. It is one of the poorest areas of Japan, a large and highly advanced economy, and is located on the northwestern tip of the Honshu isle in Japan, some $600 \mathrm{~km}$ north of Tokyo. One could make the claim, therefore, that the Tsugaru District can serve as an extreme case that may hold lessons for other rural backwaters elsewhere in advanced economies.

R. C. Kloosterman $(\bowtie)$

Amsterdam Institute of Social Science Research, Department of Geography,

Planning and International Development Studies, FMG/University of Amsterdam,

Amsterdam, The Netherlands

e-mail: R.C.Kloosterman@uva.nl 
This study is based on extensive fieldwork and historical research for a $\mathrm{PhD}$ project. The author is well versed in more contemporary research on the relationship between place and culture, is able to read Japanese, thus has access to a whole array of primary sources (e.g., public policy documents, newspaper articles, key informants in the area, etc.), and deploys a systematic and analytical approach. On the basis of this, he can paint a rich and complex tapestry of the region and its particular cultural industries and draw more general lessons.

The book starts with a potted history of the Tsugaru District of Aomori Prefecture. To cut the costs of administration and service provision, the national Japanese government decided, in the first decade of the twenty-first century, to merge a large number of small municipalities and create larger entities. Even after the merger, Aomori Prefecture continued to run a deficit, making the case for local revitalization even clearer than before. One road to go down, then, is to boost local cultural industries. This approach, though never completely absent, has become more popular and ever more products now compete on esthetic aspects to make cultural industries engines of growth in advanced economies. This holds for cities with their museums, galleries, and production of cultural products from design to films, but also for rural areas that can emphasize their strong traditions in, for instance, the making of wine or music. Governments seek to build on these cultural industries to boost employment and economic growth in the region. In this remote part of Japan, two obvious candidates can be identified for such an approach. The first one is the Tsugaru Nuri lacquerware which focuses on making eating utensils. This industry started through patronage by the local feudal and military elite during the early Edo period in the seventeenth century. The flipside of the remoteness of the area was its strategic importance in controlling access from the sea to northern Honshu which resulted in a significant military presence. A strong local demand for lacquerware (including saddles and sword scabbards) kick started the local industry. The second candidate has altogether different origins. Tsugaru Shamisen music did not grow under elite patronage but was the prerogative of blind men, “... who chanted historical narratives while performing the biwa (lute) in exchange for alms while organized in so-called $t \bar{\delta} \bar{\delta}-z a "$ (p. 29). In this case, the remoteness of the area served to preserve the legacy of this particular kind of music.

Rausch then constructs an analytical framework encompassing place, processes of production, and consumption. Building on the work of, among other, Allen Scott and Walter Santagata, he identifies "a cohesive community able to act on accumulated technical knowledge and social capital, public financial support along the entire chain of value creation and the construction of public infrastructures, a large and qualified labor market ... a high rate of new enterprise establishment and high levels of innovation ..." (p. 35) as a necessary condition for industrial districts. The presence of such a "thick" community is, however, debatable if only because the numbers involved in both cultural industries are fairly small. In 2005, there were no more than about 150 workers in 100 establishments in the Tsugaru lacquerware production. From this point of view, a revitalization policy based on local cultural industries is very much a shot in the dark.

Rausch then analyzes the revitalization policies which, notwithstanding the uncertain local conditions, have been focused on both cultural industries. The author 
starts with investigating the presence of a local identity, though in a much more modest fashion than the "cohesive community" just mentioned. On the basis of surveys and newspaper articles, he finds a pronounced local identity that should underpin a local revitalization policy. The 2005 Aomori Prefecture apparently came to a similar conclusion, and in its comprehensive plan, the consumption of local products as well as tourism were explicitly identified as potential sources of local development. The policies were aimed at promoting tourism, product branding, and product quality, together with local financing, cooperation between industry, government and research, and local consumption of local products. Strengthening the local identity and promoting the commodification of cultural resources were also part of this comprehensive scheme of economic policy informed by "soft institutionalism". Whereas the Tsugaru Shamisen was neglected by the policymakers, the Tsugaru lacquerware production was clearly present in the minds of the policymakers. Support for training facilities, technological improvements, product information, and promotional activities were made available. This attentional bias toward lacquerware and the neglect of the Shamisen music and performance tradition, however, turned out to have rather unexpected outcomes as Rausch shows.

The key problem lies in the market orientation of the producers involved. One could say that in cultural industries, success occurs at both ends of a continuum representing the importance of product innovation. Cultural industries can be highly successful through constant product innovation, thereby catering to highly fashionsensitive customers (say Prada), or they can be successful by stressing the nearimmutable qualities of their product (say Belgian beer brewed in monasteries dating from the Middle Ages). This does not imply that no innovation is possible in the case of the latter where innovation can take place in other parts of the value chain, for example, in supply, marketing, and distribution. In between the two poles, one runs the risk of not being sufficiently fashionable or of diluting the age-old character of the product and thus losing appeal. Shifting from one pole to another is therefore a very risky business. For the Tsugaru lacquerware production, this turned out to be the case. After the Edo period, the production of lacquerware became industrialized, thereby shifting to more uniform, standardized products. While this was quite a successful strategy for about a century (1870-1970), the move to a more designintensive line of products with smaller series proved to be difficult. Only recently did Tsugaru artisan entrepreneurs depart from these more uniform designs and turn to product innovation, creating more unique 'modern-traditional' products by, for instance, applying lacquer on larger furniture objects and thus getting away from eating utensils, tea-service sets, and bowls.

The Tsugaru Shamisen, which started on the margins of society, moved along a very different trajectory. This music of outcasts became popular through radio and TV broadcasts and developed along the way without losing its "authentic" core rooted in the Tsugaru District. Over a 100,000 Shamisen amateur players provide a clientele of connoisseurs and constitute a strong stimulus for professional musicians to come up with really good music which (given the size and the composition of the clientele) can be either highly traditional or stylistically innovative. Different forms are, hence, not necessarily competing with each other but may complement each other as each caters to a different market segment. Moreover, biographies of famous 
musicians from the Tsugaru District contributed to processes of place creation and, hence, to tourism. Tsugaru Shamisen thus followed a trajectory which resembles that of black music in the United States. Without direct government support, then, this particular cultural industry was quite successful and able both to build on localized resources, which cannot be copied easily elsewhere, and to open up new markets not just in Japan but also abroad.

The point has been made before, but Rausch provides ample evidence for the view that no one-size-fits-all policy for revitalization through the fostering of local cultural industries exists. On the basis of his findings for two cultural industries in the Tsugaru District, he concludes that the historical trajectory of a particular cultural industry and its current position may be (much) more important than a conscious government policy. By presenting a conceptual framework organized around the notions of place, production, and consumption of culture, and empirically exploring place-based cultural commodities in a Japanese backwater, Anthony Rausch has made a very useful contribution to debates on cultural industries, local development policies, and rural development. The role of consumption and consumers is often neglected, but here it is integrated in a meaningful way.

Nothing is perfect in the real world, and that holds true for this study as well. I missed the role of gatekeepers and tastemakers in creating and maintaining demand for cultural products. These intermediaries-such as life style magazines, travel programmes on the TV—can be crucial in the process of making product and place images. In addition, the author underestimates the extent to which added value created in a particular place or region can leak away to a city higher up the urban hierarchy. Lastly, for local development through cultural industries, a specific kind of entrepreneurship is needed: one that has deep knowledge of local resources but is also very much aware of the larger market out there. This kind of entrepreneurship turns out to be rather rare. But these are just minor shortcomings.

Open Access This article is distributed under the terms of the Creative Commons Attribution Noncommercial License which permits any noncommercial use, distribution, and reproduction in any medium, provided the original author(s) and source are credited. 